\title{
A novel collaborative approach to endoscopic double bypass in concomitant gastric outlet and biliary obstruction
}

Endoscopic ultrasound (EUS)-guided double bypass (EUS-DB) is a novel technique in the management of concomitant biliary and gastric outlet obstruction [1 - 3]. It involves the creation of both an EUS-guided gastroenterostomy and a hepatogastrostomy. We describe the first reported case in the literature (with video) of EUS-DB performed in collaboration with interventional radiology.

A 54-year-old man with known locally advanced pancreatic cancer was referred for recurrent cholangitis and gastric outlet obstruction despite previous duodenal stenting and transhepatic percutaneous biliary drainage (PTBD). Endoscopy confirmed complete obstruction of the duodenal stent as a result of tumor tissue ingrowth. A decision was made to proceed to EUS-DB to optimize nutritional status, biliary drainage, and patient comfort ( $\vee$ Video 1).

A guidewire was introduced through the PTBD, traversing the enteral stent, and advanced to the jejunum. A $20-\mathrm{mm}$ dilating balloon with an overlapping snare attached was then introduced over the PTBD wire and advanced across the enteral stent to the ligament of Treitz, where the balloon was inflated under fluoroscopy ( $\triangleright$ Fig. 1 a). Overall, $500 \mathrm{~mL}$ of both saline and contrast was then injected per-

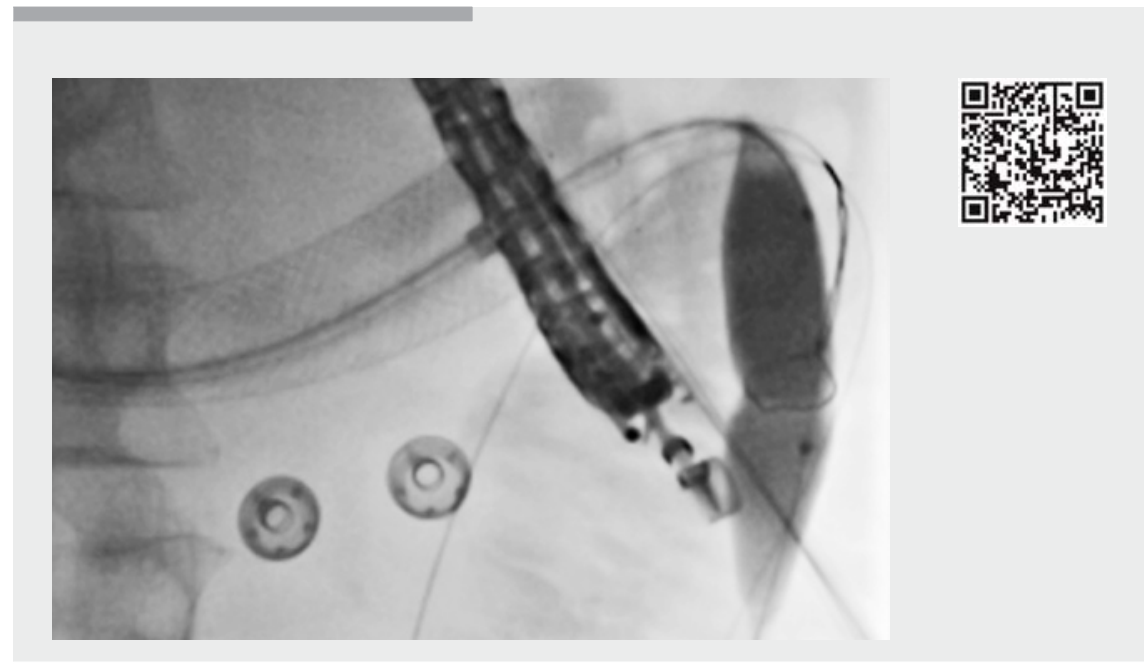

Video 1 Successful endoscopic ultrasound-guided double bypass in collaboration with interventional radiology.

cutaneously to dilate the small-bowel segment proximally to the balloon. EUS-guided puncture of the balloon was performed transgastrically with a 19-gauge needle ( $\mathbf{F i g} \mathbf{1} \mathbf{b})$. Bursting of the balloon confirmed successful puncture in the desired jejunal segment. A 0.035 -inch guidewire was then advanced through the needle, grasped with the snare, and pulled through the percutaneous access, thereby creating wire tension on both ends of the wire. Track dilation was performed with a $4 \mathrm{~mm}$ dilating balloon. A lumen-apposing metal stent $(15 \times 10 \mathrm{~mm})$ was then deployed under EUS guidance ( $\mathbf{F i g} \cdot \mathbf{1}$ c). Contrast injection confirmed a patent gastroenterostomy.

Attention was then shifted to the hepatogastrostomy. Under EUS guidance, a dilated hepatic segment III left intrahepatic bile duct was visualized. A transgastric
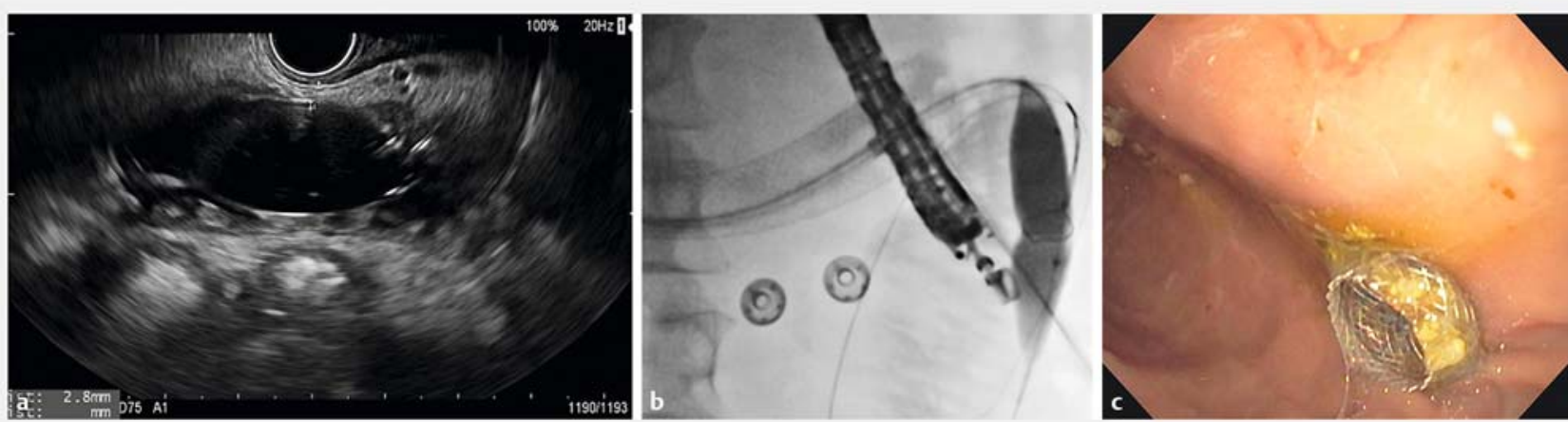

- Fig. 1 Imaging studies. a Endoscopic ultrasound (EUS) view of the inflated balloon in the jejunum, distal to the obstruction site. b Fluoroscopic view of the EUS-guided needle puncture of the inflated balloon. $\mathbf{c}$ Endoscopic view of full deployment of the lumen-apposing metal stent. 


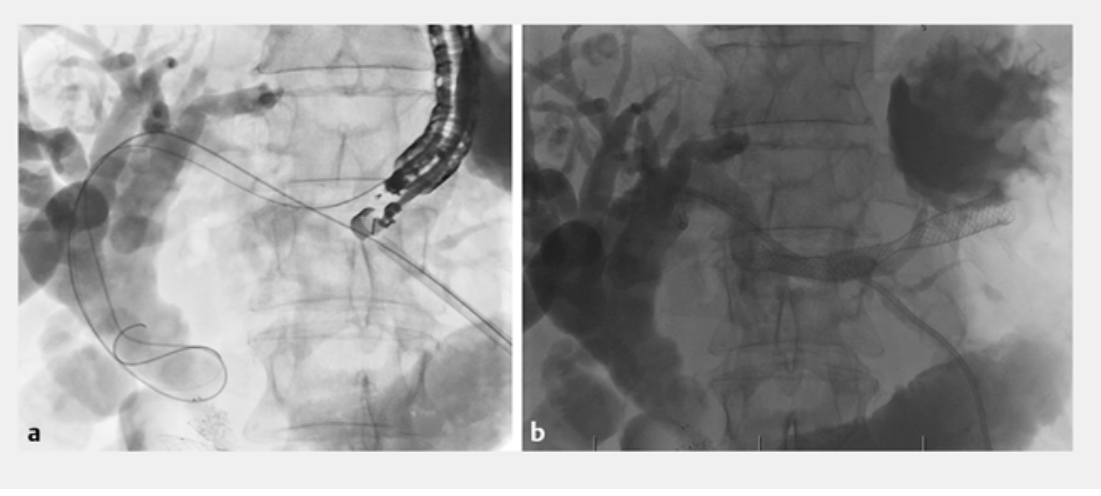

- Fig. 2 Fluoroscopic view. a Transgastric guidewire coiled in the hepatic hilum. b The fully deployed 80-mm, partially covered, self-expandable metal stent forming hepatogastrostomy.

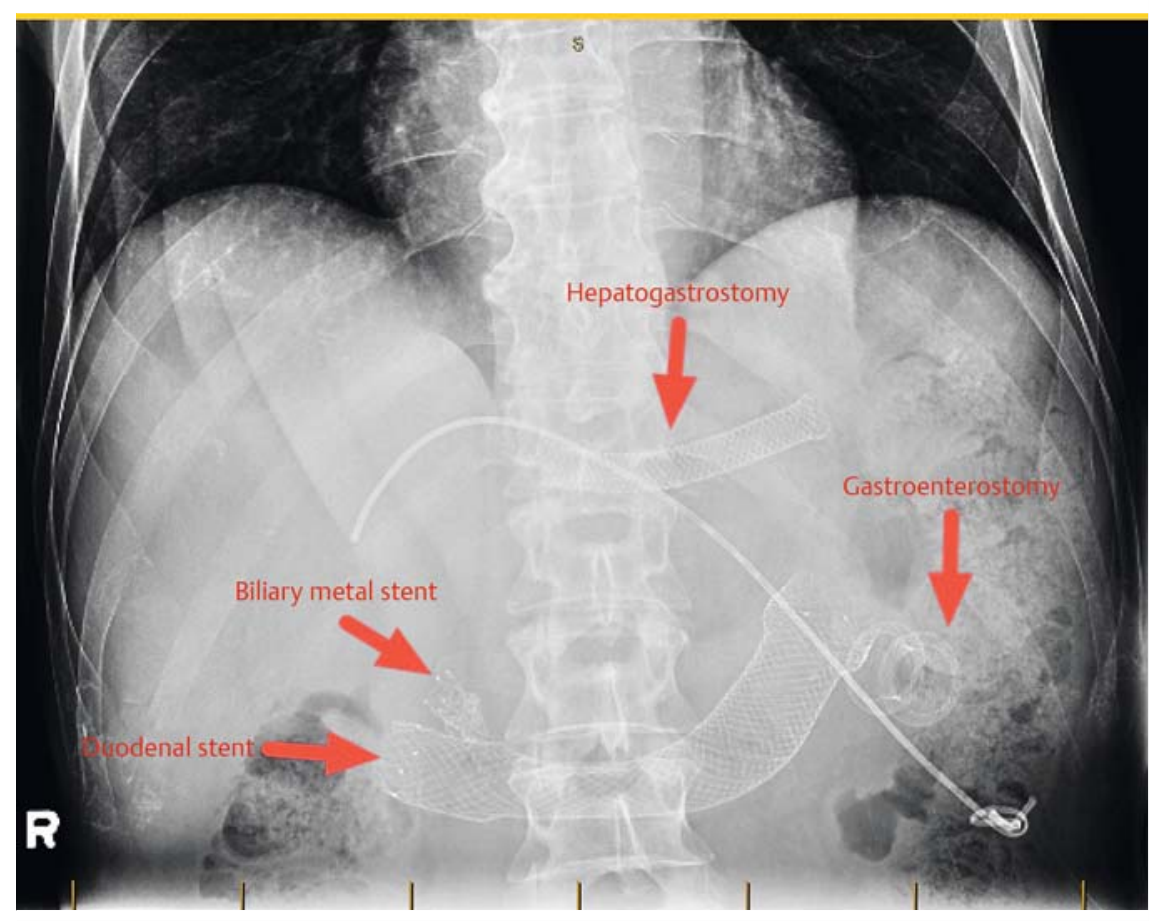

- Fig. 3 Post-procedural abdominal radiograph, showing all stents in place. puncture of the duct was performed with a 19-gauge needle, followed by the advancement of a 0.035 -inch guidewire into the common bile duct ( $>$ Fig. 2 a). The hepatogastrostomy track was then dilated using a 4-mm dilating balloon, followed by successful deployment of a $10 \times 80 \mathrm{~mm}$ partially covered, self-expandable metal stent ( Fig. 2 b, > Fig. 3).

A full, low-residue diet was initiated 48 hours post-procedure, with excellent tolerance. The PTBD was removed 3 days later. Bilirubin levels had decreased by more than $50 \%$ at the 1 -week follow-up. We describe the first reported EUS-guided double bypass performed in collaboration with interventional radiology. Combining endoscopic and interventional radiology techniques may enhance the safety and ease of this novel approach. However, further studies will be needed to validate this new approach.

Endoscopy_UCTN_Code_TTT_1AO_2AI

\section{Competing interests}

Dr. Chen is a consultant for Boston Scientific. Dr. Valenti is a previous speaker for Boston Scientific and Cook Medical. Dr. Barkun has served as a consultant for Cook Inc., Pendopharm Inc., and Olympus. He has also received research support and served on an advisory committee for Olympus, and has received funds from Cook Inc., Pendopharm Inc.

The authors

Ahmad Hashim ${ }^{1}$, Corey Miller ${ }^{1}$, Ali Bessissow ${ }^{2}$, David Valenti ${ }^{2}$, Alan Barkun ${ }^{1}$, Jeffrey Barkun ${ }^{3}$, Yen-I Chen ${ }^{1}$

1 Division of Gastroenterology and Hepatology, McGill University Health Center, Montreal, Canada

2 Division of Interventional Radiology, McGill University Health Center, Montreal, Canada

3 Department of Surgery, McGill University Health Center, Montreal, Canada 


\section{Corresponding author}

\section{Yen-I Chen, MD}

Division of Gastroenterology and

Hepatology, McGill University Health Centre, 1001 Decarie Blvd, Montreal, QC, H4A 3J1,

Canada

yen-i.chen@mail.mcgill.ca

\section{References}

[1] Khashab MA, El Zein M, Ngamruengphong S et al. Double endoscopic bypass by using lumen-apposing stents (with videos). Gastrointest Endosc 2016; 83: 435-439
[2] Brewer Gutierrez OI, Nieto J, Irani S et al. Double endoscopic bypass for gastric outlet obstruction and biliary obstruction. Endosc Int Open 2017; 5: E893 - E899

[3] Chen YI, Khashab MA. Endoscopic approach to gastrointestinal bypass in malignant gastric outlet obstruction. Curr Opin Gastroenterol 2016. doi:10.1097| MOG.0000000000000292

\section{Bibliography}

DOI https://doi.org/10.1055/a-0625-6154

Published online: 19.6.2018

Endoscopy 2018; 50: E237-E239

(C) Georg Thieme Verlag KG

Stuttgart · New York

ISSN 0013-726X
ENDOSCOPY E-VIDEOS

https://eref.thieme.de/e-videos

回局 Endoscopy E-Videos is a free Fection, reporting 回舴: on interesting cases and new techniques in gastroenterological endoscopy. All papers include a high quality video and all contributions are freely accessible online.

This section has its own submission website at

https://mc.manuscriptcentral.com/e-videos 